\title{
Clinical Study \\ Different Types of Resistant Starch Elicit Different Glucose Reponses in Humans
}

\author{
Mark D. Haub, ${ }^{1}$ Kelcie L. Hubach, ${ }^{1}$ Enas K. Al-tamimi, ${ }^{1}$ Sammy Ornelas, ${ }^{1}$ and Paul A. Seib ${ }^{2}$ \\ ${ }^{1}$ Human Metabolism Laboratory, Department of Human Nutrition, Kansas State University, Manhattan, KS 66506, USA \\ ${ }^{2}$ Department of Grain Science and Industry, Kansas State University, Manhattan, KS 66506, USA
}

Correspondence should be addressed to Mark D. Haub, haub@ksu.edu

Received 6 July 2009; Accepted 4 September 2009

Academic Editor: Michael Pagliassotti

Copyright (C) 2010 Mark D. Haub et al. This is an open access article distributed under the Creative Commons Attribution License, which permits unrestricted use, distribution, and reproduction in any medium, provided the original work is properly cited.

\begin{abstract}
The purpose of this study was to determine whether different types of resistant starch (RS) elicited different glycemic responses. Eleven healthy subjects consumed solutions containing $30 \mathrm{~g}$ of either dextrose (DEX), resistant starch type 2 (RS2), or cross-linked resistant wheat starch type $4\left(\mathrm{RS}_{\mathrm{XL}}\right)$ on three separate occasions, which were assigned randomly. Finger stick blood samples were collected before and over the following two hours and measured for glucose. The incremental area under the curve (iAUC) for the glucose response was calculated for all trials. The two types of resistant starch significantly $(P<.05)$ decreased iAUC compared with DEX. The response with RS4 $4_{\mathrm{XL}}$ was significantly decreased compared with the RS2 trial. These data demonstrate that different types of resistant starch elicit significantly different glycemic responses.
\end{abstract}

\section{Findings}

Foods containing resistant starch (RS) generally give a low glycemic response because RS is not digested in the small intestine. Instead RS passes into the large intestine where it is fermented [1-8]. Starch can escape digestion if it is embedded in a matrix that renders the starch inaccessible to enzymes (type 1, RS1). In addition, some untreated starch granules are known to resist digestion (RS2). Again, starch which is cooked and cooled, nongranular, and sometimes debranched, forms RS when it reassociates and recrystallizes (RS3). Finally, starches that are structurally modified become resistant (RS4).

Examples of RS2 also include untreated granules of potato, green bananas, and high-amylose maize starches. When boiled in water, potato, and banana starches lose their resistance, but high-amylose maize starch, being difficult to cook, partially retains granular structure and resistance to digestion. Hydrothermal treatment of high-amylose maize starch enhances its level of RS [7,9]. Examples of RS4 are cross-linked starches [10-12], starch esters [13], starch ethers, [14] and pyrodextrins with new glycosidic linkages differing from alpha-1, 4 and alpha-1, 6 bonds $[7,15]$.
The swelling and solubilities of RS2 from high-amylose (70\%) maize starch and RS4 $\mathrm{XL}_{\mathrm{L}}$ are much lower than normal cereal starches in both cold and hot water [11, 16, 17]. At $95^{\circ} \mathrm{C}$ in excess water RS4XL showed a swelling power of $2.8 \mathrm{~g} / \mathrm{g}$ and solubility of $0.5 \%$ compared to untreated wheat starch at $7.6 \mathrm{~g} / \mathrm{g}$ and $27.7 \%$ [17]. Hydrothermally treated high-amylose (70\%) maize starch (Novelose 240, which contains less RS than Novelose 260) did not change granular structure when heated in water up to $85^{\circ} \mathrm{C}$ [16], and it showed a swelling power at $95^{\circ} \mathrm{C}$ of $2.1 \mathrm{~g} / \mathrm{g}$ and solubility of $1.9 \%$ [17].

Most clinical trials to date have used RS2 as the ingredient of choice for studies investigating the glucose lowering potential of RS. There is a paucity of research on the clinical outcomes of other types, especially RS4. Wheat-derived RS4 ${ }_{\mathrm{XL}}$ may have greater potential at decreasing the glucose response as it contains a high degree of dietary fiber and RS [18], but there has only been one clinical trial testing its efficacy at lowering blood glucose [19]. Furthermore, there are limited, if any, studies that have compared the health outcomes of various types of RS, which makes it difficult to fully understand the beneficial capacity of RS to assist with glucose control. Thus, the aim of this clinical 
trial (NCT00930956; ClinicalTrials.gov) was to determine whether RS2 (the most commonly tested type of RS) and RS4XL elicit similar glucose responses.

\section{Research Design and Methods}

The volunteers (females $n=7$, males $n=4$; age $=24 \pm 4 \mathrm{yr}$; ht $=1.65 \pm 0.07 \mathrm{~m} ; \mathrm{wt}=63.7 \pm 13.1 \mathrm{~kg} ; \mathrm{BMI}=23.2 \pm$ $3.8 \mathrm{~kg} / \mathrm{m}^{2}$ ) were not diagnosed with any chronic disease. The Institutional Review Board of Kansas State University approved the study, and all volunteers provided written informed consent.

Each volunteer visited the laboratory in a 10-12 hour fasted state on three occasions over a three-week period, up to two visits/wk, with at least 48 hours between visits. Volunteers were asked to refrain from vigorous physical activity and the consumption of alcohol the day before each testing visit. Randomization using a Latin Square design was applied to minimize confounding issues associated with the order of administration. Each volunteer consumed $30 \mathrm{~g}$ of carbohydrate in the following forms: $178 \mathrm{~mL}$ of a dextrose beverage (DEX; Sun-Dex); resistant starch type 2 diluted in $178 \mathrm{~mL}$ of water (RS2; Hi-Maize 260); cross-linked resistant wheat starch diluted in $178 \mathrm{~mL}$ of water $\left(\mathrm{RS} 4_{\mathrm{XL}}\right.$; Fibersym RW). The dose was established from a prior study showing improved insulin sensitivity using RS2 [20]. The use of the DEX treatment was to provide a reference from which to compare the other treatments, and allow for determining a relative glycemic response.

In the morning of each test, finger-prick capillary blood samples were collected to determine fasting (baseline) blood glucose levels. The volunteers then consumed the test solution assigned for that trial. Ten minutes were allowed for the test solution to be consumed. Over the two hours following the start of each test, finger-prick capillary blood samples were collected at 30, 60, 90, and 120 minutes. Blood glucose levels were immediately measured in duplicate using an automated blood glucose analyzer (YSI 2300, Yellow Springs, Ohio, USA). Analysis of the collected sample was repeated if the difference between duplicate samples was greater than $0.1 \mathrm{mmol} / \mathrm{L}$. Once the samples were analyzed, the data was entered and the incremental area under the curve was calculated using the trapezoidal model (GraphPad v5.0, La Jolla, Calif, USA).

Statistical Analysis. Paired $t$-tests were used to determine significant differences between treatments at each time point and to determine differences between iAUC values; significance was set at $P=.05$. The data was statistically analyzed using SPSS software (v13.0; Chicago, Ill, USA).

\section{Results}

The numerical peak in glucose for the DEX and RS2 treatments occurred at 30 minutes, while the glucose peak during the RS4XL treatment did not occur until 120 minutes (Figure 1(a)). The iAUC for each treatment was different from one another (Figure 1(b)). The DEX trial elicited an

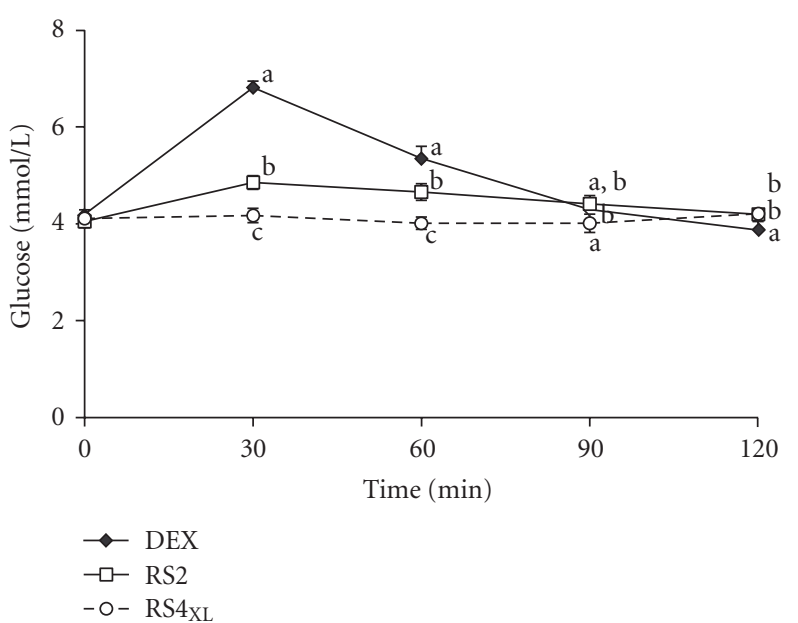

(a)

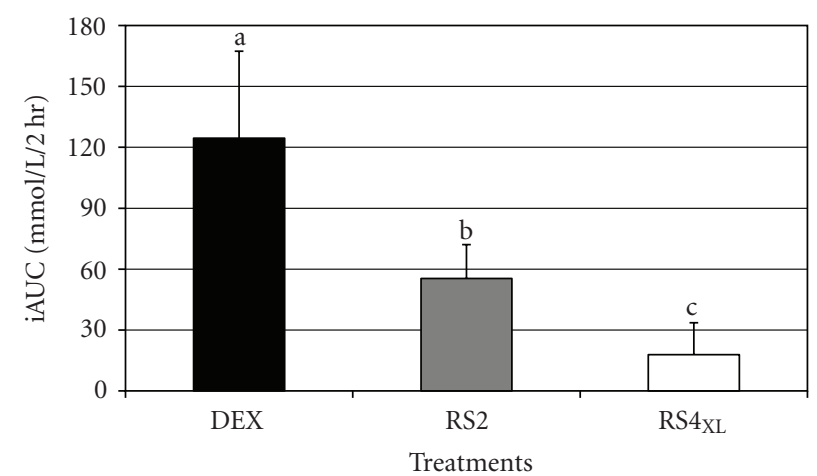

(b)

FIgURE 1: The glucose responses to $30 \mathrm{~g}$ of carbohydrate from three treatments (DEX, RS2 and RS4 ${ }_{\mathrm{XL}}$ ). Panel (a) depicts the glucose changes over time, while panel (b) depicts the incremental area under the glucose curve. Data presented are mean \pm SE; significance was set at $P<.05$; and, different letters indicate difference between treatments.

increased iAUC compared with RS2 $(P=.001)$ and RS4 $(P=.000)$, while the iAUC for RS2 was increased compared with $\mathrm{RS}_{\mathrm{XL}}(P=.002)$. The relative glycemic responses were $100 \%, 34.9 \pm 11 \%$, and $11.3 \pm 10 \%$ for DEX, RS2, and $\mathrm{RS} 4 \mathrm{XL}$, respectively.

\section{Conclusions}

This randomized clinical study demonstrates that different types of RS elicit different glycemic responses. This study supports prior studies where RS attenuated the glucose response [19-25], as both types of RS in the present study attenuated the glucose response compared with the same amount dextrose. However, these data indicate that not all RS types elicit similar glucose responses, as the $\mathrm{RS} 4_{\mathrm{XL}}$ response was less than RS2. A reason for this observation is likely that $\mathrm{RS} 4 \mathrm{XL}$ contains a greater degree of dietary fiber $(91.9 \%)$ and more RS (83\%) [18] compared with the fiber $(60 \%)$ and RS content $(46 \%)$ of the version of RS2 that was used [26]. This is a critical application issue since companies use 
these functional starches as ingredients in food products. As an ingredient, these results indicate that based on a weight comparison, the RS4 $\mathrm{XL}_{\mathrm{L}}$ elicits a greater capacity to attenuate the glucose response. Additionally, it has previously been demonstrated that RS4XL attenuates blood glucose and insulin responses when incorporated in food [19].

This study is limited by the fact that the volunteers consumed the ingredients as is which this is not the form that these ingredients are typically consumed. However, to determine glucoregulatory differences between types of RS, this approach of direct unprocessed comparison is necessary to determine how processing or cooking can affect the level of $\mathrm{RS}$ remaining in a food [18]. Future studies should compare other types of raw RS to determine which offers the greatest glucose lowering potential. Additionally, these different types need to be compared in typical food applications. All in all, both types of RS elicited a lower blood glucose response in vivo; however, the type of RS needs to be considered because the glucose lowering capacity can differ significantly.

\section{Abbreviations}

DEX: Dextrose trial

iAUC: Incremental area under the curve

RS: Resistant starch

RS2: Resistant starch type 2

RS4: Resistant starch type 4

$\mathrm{RS}_{\mathrm{XL}}$ : Cross-linked resistant wheat starch, type 4 RS.

\section{Competing Interests}

Drs. M. D. Haub and P. A. Seib have received funding support from MGP Ingredients, Inc over the past five years. None of the authors will be financially affected (gain or loss) by the publication of this manuscript.

\section{Authors' Contributions}

E. K. Al-tamimi, K. L. Hubach and S. Ornelas organized and conducted the research for this study, and edited initial drafts of the manuscript. E. K. Al-tamimi and K. L. Hubach assisted with data analysis. P. A. Seib guided the research design, provided critical intellectual content, and edited the manuscript. M. D. Haub was the principle investigator, designed the study, assisted E. K. Al-tamimi, K. L. Hubach and S. Ornelas with sample collection/analysis and data analysis, and wrote the majority of the manuscript.

\section{Acknowledgments}

This study was supported in part by funds from the American Heart Association (0560026Z) and the United States Department of Agriculture (CSREES/Hatch, no. KS347) these funding sources supported the salary for E. K. Altamimi and K. L. Hubach and were used to purchase all materials and supplies for this study.

\section{References}

[1] I. L. Brown, K. J. McNaught, D. Andrews, and T. Morita, "Resistant Starch: plant breeding, applications, development and commercial uses," in Advanced Dietary Fibre Technology, B. V. McCleary and L. Prosky, Eds., Iowa State University Press, Blackwell Science, Ames, Iowa, USA, 2001.

[2] K. N. Englyst, S. Liu, and H. N. Englyst, "Nutritional characterization and measurement of dietary carbohydrates," European Journal of Clinical Nutrition, vol. 61, supplement 1, pp. S19-S39, 2007.

[3] J. A. Higgins, D. R. Higbee, W. T. Donahoo, I. L. Brown, M. L. Bell, and D. H. Bessesen, "Resistant starch consumption promotes lipid oxidation," Nutrition and Metabolism, vol. 1, article 8, 2004.

[4] D. J. A. Jenkins and C. W. C. Kendall, "Resistant starches," Current Opinion in Gastroenterology, vol. 16, no. 2, pp. 178$183,2000$.

[5] A. P. Nugent, "Health properties of resistant starch," Nutrition Bulletin, vol. 30, no. 1, pp. 27-54, 2005.

[6] M. G. Sajilata, R. S. Singhal, and P. R. Kulkarni, "Resistant starch-a review," Comprehensive Reviews in Food Science and Food Safety, vol. 5, no. 1, pp. 1-17, 2006.

[7] D. B. Thompson, "Resistant starch," in Functional Food Carbohydrates, C. G. Biliaderis and M. Izydorczyk, Eds., pp. 73-96, CRC Press, Boca Raton, Fla, USA, 2007.

[8] A. Sharma and B. S. Yadav, "Resistant starch: physiological roles and food applications," Food Reviews International, vol. 24, no. 2, pp. 193-234, 2008.

[9] Y. C. Shi and R. Jeffcoat, "Structural features of resistant starch," in Advanced Dietary Fibre Technology, B. V. McCleary and L. Prosky, Eds., pp. 430-439, Iowa State University Press, Blackwell Science, Ames, Iowa, USA, 2008.

[10] A. Aparicio-Saguilan, F. Gutierrez-Meraz, F. J. Garcia-Suarez, J. Tovar, and L. A. Bello-Perez, "Physicochemical and functional properties of cross-linked banana resistant starch. Effect of pressure cooking," Starch, vol. 60, no. 6, pp. 286-291, 2008.

[11] K. S. Woo and P. A. Seib, "Cross-linked resistant starch: preparation and properties," Cereal Chemistry, vol. 79, no. 6, pp. 819-825, 2002.

[12] X. Xie and Q. Liu, "Development and physicochemical characterization of new resistant citrate starch from different corn starches," Starch, vol. 56, no. 8, pp. 364-370, 2004.

[13] J. M. Clarke, A. R. Bird, D. L. Topping, and L. Cobiac, "Excretion of starch and esterified short-chain fatty acids by ileostomy subjects after the ingestion of acylated starches," American Journal of Clinical Nutrition, vol. 86, no. 4, pp. 11461151, 2007.

[14] B. M. N. M. Azemi and M. Wootton, "Invitro digestibility of hydroxypropyl maize, waxy maize and high amylose maize starches," Starke, vol. 36, pp. 273-275, 1984.

[15] K. Ohkuma and S. Wakabayashi, "Fibersol-2: a soluble, nondigestible, starch-derived dietary fiber," in Advanced Dietary Fibre Technology, B. V. McCleary and L. Prosky, Eds., pp. 509523, Iowa State University Press, Blackwell Science, Ames, Iowa, USA, 2001.

[16] W. S. Ratnayake and D. S. Jackson, "Thermal behavior of resistant starches RS 2, RS 3, and RS 4," Journal of Food Science, vol. 73, no. 5, pp. C356-C366, 2008.

[17] M. Shin, K. Woo, and P. A. Seib, "Hot-water solubilities and water sorptions of resistant starches at $25^{\circ} \mathrm{C}$," Cereal Chemistry, vol. 80, no. 5, pp. 564-566, 2003.

[18] L. L. Yeo and P. A. Seib, "White pan bread and sugar-snap cookies containing wheat starch phosphate, a cross-linked 
resistant starch," Cereal Chemistry, vol. 86, no. 2, pp. 210-220, 2009.

[19] E. K. Al-tamimi, P. A. Seib, B. S. Snyder, and M. D. Haub, "Consumption of cross-linked resistant starch (RS4 $\left.4_{\mathrm{XL}}\right)$ on glucose and insulin responses in humans," Journal of Nutrition and Metabolism, vol. 2010, Article ID 651063, 6 pages, 2010.

[20] M. D. Robertson, A. S. Bickerton, A. L. Dennis, H. Vidal, and K. N. Frayn, "Insulin-sensitizing effects of dietary resistant starch and effects on skeletal muscle and adipose tissue metabolism," American Journal of Clinical Nutrition, vol. 82, no. 3, pp. 559-567, 2005.

[21] P. M. Heacock, S. R. Hertzler, and B. Wolf, "The glycemic, insulinemic, and breath hydrogen responses in humans to a food starch esterified by 1-octenyl succinic anhydride," Nutrition Research, vol. 24, no. 8, pp. 581-592, 2004.

[22] A. C. Nilsson, E. M. Ostman, J. J. Holst, and I. M. E. Bjorck, "Including indigestible carbohydrates in the evening meal of healthy subjects improves glucose tolerance, lowers inflammatory markers, and increases satiety after a subsequent standardized breakfast," Journal of Nutrition, vol. 138, no. 4, pp. 732-739, 2008.

[23] D. M. Reader, B. S. O'Connell, M. L. Johnson, and M. Franz, "Glycemic and insulinemic response of subjects with type 2 diabetes after consumption of three energy bars," Journal of the American Dietetic Association, vol. 102, no. 8, pp. 1139-1142, 2002.

[24] M. D. Robertson, J. M. Currie, L. M. Morgan, D. P. Jewell, and K. N. Frayn, "Prior short-term consumption of resistant starch enhances postprandial insulin sensitivity in healthy subjects," Diabetologia, vol. 46, no. 5, pp. 659-665, 2003.

[25] Y. Yamada, S. Hosoya, S. Nishimura, et al., "Effect of bread containing resistant starch on postprandial blood glucose levels in humans," Bioscience, Biotechnology and Biochemistry, vol. 69, no. 3, pp. 559-566, 2005.

[26] R. K. Le Leu, Y. Hu, I. L. Brown, and G. P. Young, "Effect of high amylose maize starches on colonic fermentation and apoptotic response to DNA-damage in the colon of rats," Nutrition and Metabolism, vol. 6, article 11, 2009. 


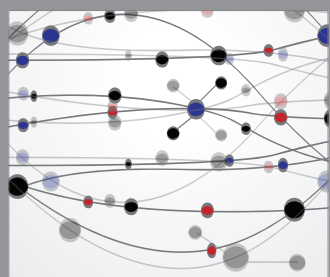

The Scientific World Journal
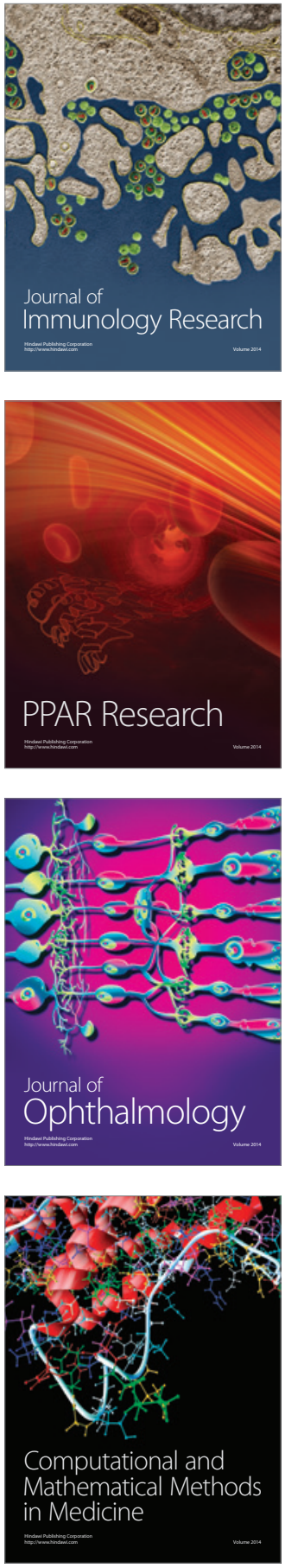

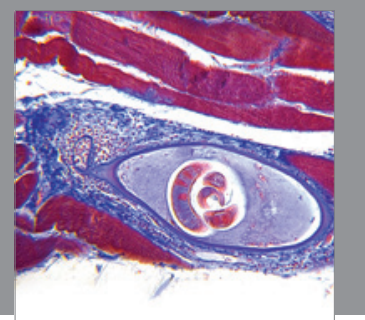

Gastroenterology

Research and Practice
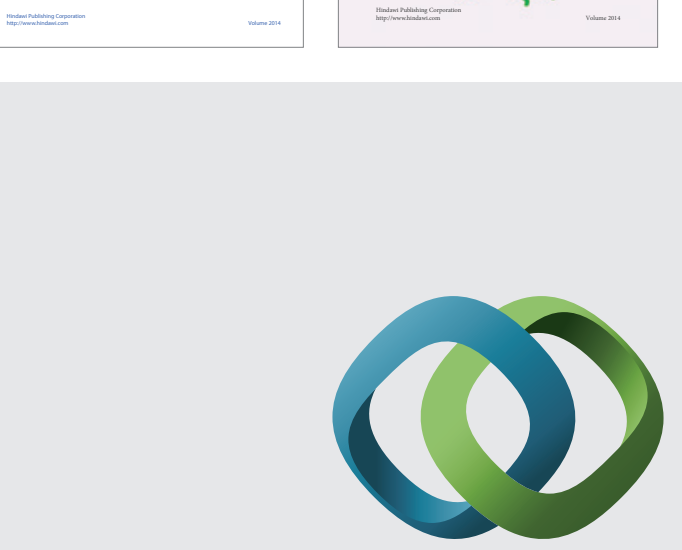

\section{Hindawi}

Submit your manuscripts at

http://www.hindawi.com
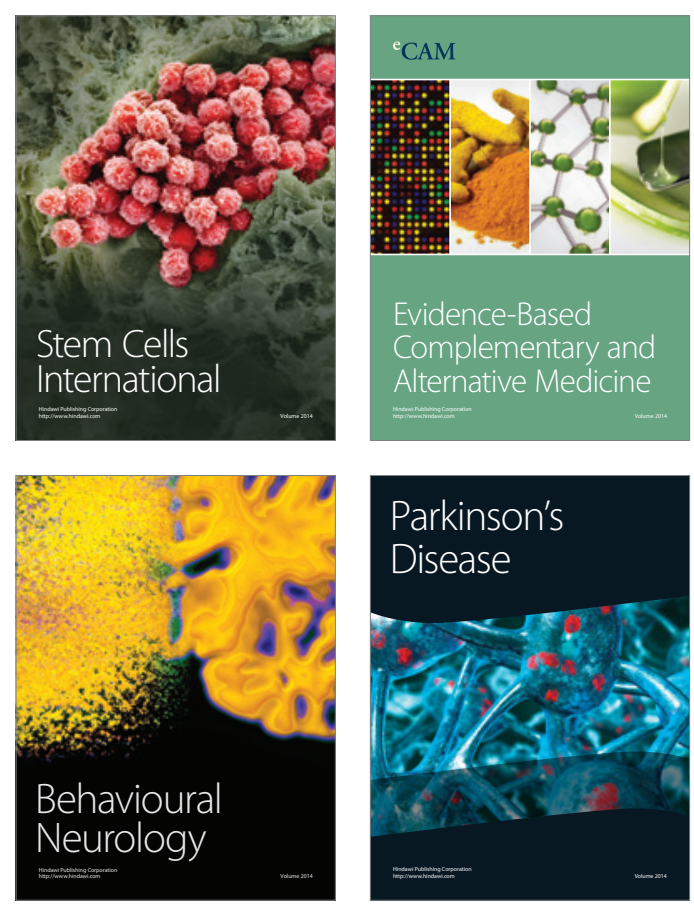

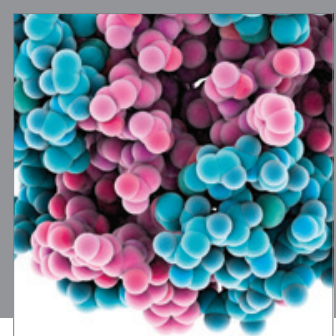

Journal of
Diabetes Research

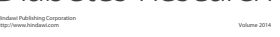

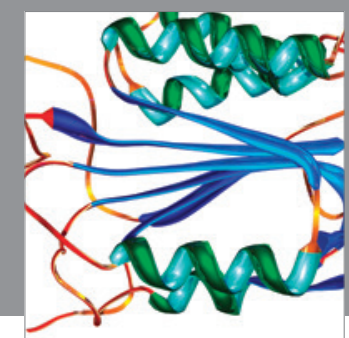

Disease Markers
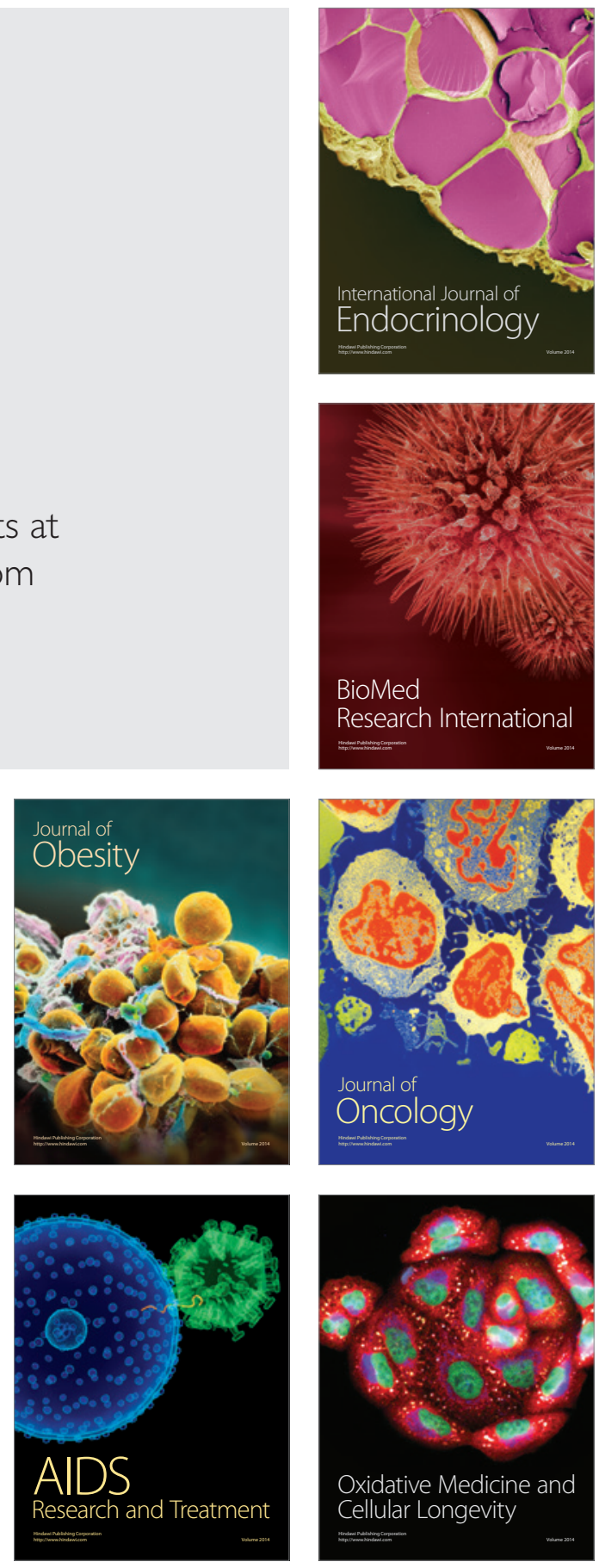